\title{
GAMBARAN ANGKA DROP OUT PADA PENGGUNAAN TERAPI RUMATAN METADON DI PUSKESMAS SENEN, PUSKESMAS GAMBIR DAN PUSKESMAS KEMAYORAN JAKARTA PUSAT PADA TAHUN 2014-2016 DAN TINJAUANNYA MENURUT ISLAM
}

\author{
Zulha Annisa Ichwan', Bambang Poerwantoro'2, Zuhroni ${ }^{3}$ \\ ${ }^{1}$ Fakultas Kedokteran Universitas YARSI \\ ${ }^{2}$ Bagian Medikolegal Fakultas Kedokteran Universitas YARSI \\ ${ }^{3}$ Bagian Ilmu Agama Islam Fakultas Kedokteran Universitas YARSI
}

\begin{abstract}
ABSTRAK
Saat ini Indonesia berstatus darurat narkoba. Pengguna narkoba di Indonesia tercatat sebanyak 5,1 juta jiwa. Setiap tahun, sekitar 15 ribu jiwa melayang karena menggunakan narkoba. Untuk menanggulangi semua keadaan tersebut pemerintah melalui Peraturan Menteri Kesehatan, menerapkan Terapi Rumatan Metadon. Metadon bukan penyembuh untuk ketergantungan opiat: selama memakai metadon, penggunanya tetap tergantung pada opiat secara fisik. Peserta terapi rumatan metadon sering merasa diri mereka cukup sehat untuk keluar dari program terapi (drop out). Penelitian ini bertujuan untuk mengetahui angka drop out pada penggunaan terapi rumatn metadon di Puskesmas Senen, Puskesmas Gambir dan Puskesmas Kemayoran Jakarta Pusat pada tahun 2014 - 2016 dan Tinjauannya menurut Islam. Metode penelitian yang digunakan survey deskriptif dengan data retrospektif menggunakan data sekunder berupa data Drop Out pada penggunaan Metadon di Puskesmas Senen, Puskesmas Gambir dan Puskesmas Kemayoran Jakarta Pusat pada tahun 2014-2016. Hasil penelitian ini menunjukkan jumlah pasien drop out pada terapi rumatan metadon di Puskesmas Senen, Puskesmas Gambir dan Puskesmas Kemayoran dalam 3 tahun. Di Puskesmas Senen angka drop out tertinggi terjadi pada tahun 2015 yaitu sebanyak 16 pasien dari 239 pasien yang terdaftar (6,7\%). Di Puskesmas Gambir angka drop out tertinggi terjadi pada tahun 2015 yaitu 34 pasien dari 98 pasien yang terdaftar (34,7\%). Pada Puskesmas Kemayoran angka drop out tertinggi terjadi pada tahun 2015 yaitu 11 pasien dari 55 pasien yang terdaftar 20\%. Pasien drop out pada terapi rumatan metadon baik di Puskesmas Senen maupun Puskesmas Kemayoran sebagian besar adalah berjenis kelamin laki - laki dan paling banyak drop out terjadi pada kelompok umur 25 - 49 tahun yaitu, 24 pasien dari 25 pasien drop out (96\%). Angka drop out tertinggi pada ketiga puskemas terjadi pada tahun 2015. Pasien drop out sebagian besar berjenis kelamin laki-laki dan paling banyak terjadi pada kelompok umur 25 - 49 tahun. Dalam pandangan Islam penyalahgunaan narkoba hukumnya haram namun jika digunakan untuk kepentingan medis dan tidak berlebihan diperbolehkan. Ini adalah keadaan darurat dan keadaan tersebut masih diperbolehkan mengingat kaedah yang sering dikemukakan oleh para ulama, "Keadaan darurat membolehkan sesuatu yang terlarang". Untuk mengurangi angka drop out dan kekambuhan, seharusnya prinsip berobat bagi pasien pecandu NAPZA adalah berobat dan bertobat, dengan metode terpadu yaitu terapi medis, psikologis, sosial dan agama.
\end{abstract}

Kata Kunci: Terapi Rumatan Metadon; Metadon; Drop Out 


\section{ABSTRACT}

Currently Indonesia has a drug emergency status. Drug users in Indonesia was recorded as many as 5.1 million people. Every year, about 15 thousand people die from drug use. To overcome all these circumstances the government through the Regulation of the Minister of Health, apply Methadone Maintenance Therapy program. Methadone is not a cure for opiate dependency: during methadone use, the user remains dependent on opiates physically. Participants of methadone maintenance therapy often feel themselves healthy enough to get out of the therapy program (drop out). This study aims to determine the number of dropout in the use of methadone maintenance therapy at Puskesmas Senen, Puskesmas Gambir and Puskesmas Kemayoran Central Jakarta from 2014 to 2016 and overview in Islamic views. This research method used descriptive survey with retrospective data using secondary data in the form of data Drop Out on Methadone Usage at Puskesmas Senen, Puskesmas Gambir and Puskesmas Kemayoran Central Jakarta in 2014-2016. The results of this study indicate the number of patients dropped out on methadone maintenance therapy at Puskesmas Senen, Puskesmas Gambir and Puskesmas Kemayoran in 3 years. At Puskesmas Senen, the highest drop out rate occurred in 2015 with 16 patients from 239 registered patients (6.7\%). At Puskesmas Gambir, the highest drop out rate occurred in 2015 with 34 patients from 98 registered patients (34.7\%). And at Puskesmas Kemayoran, the highest drop out rate occurred in 2015 with 11 patients from 55 patients who registered (20\%). Patients dropping out on methadone maintenance therapy in both Puskesmas Senen and Kemayoran were mostly male and most dropped out at 25 to 49 years with 24 patients out of 25 drop out patients (96\%). The highest drop out rate in all three puskesmas occurred in 2015. Patients drop out most of the male and most occur in the age group of 25-49 years. In the view of Islam drug abuse is illegal but if used for medical purposes and not excessive is allowed. This is a state of emergency and the circumstances are still allowed to remember the method often raised by scholars, "The state of emergency allows forbidden things". To reduce the rate of drop out and recurrence, the principle that must be applied of treatment for drug addicts patients are treated and repented, with integrated methods of medical therapy, psychological, social and religious.

\section{Keywords: Methadone Maintenance Therapy; Methadone; Drop Out}

\section{Pendahuluan}

Indonesia merupakan negara kepulauan terbesar di dunia dan memiliki letak geografis yang unik dan strategis. Indonesia memiliki jumlah penduduk yang besar, dengan laju pertumbuhan penduduk Indonesia sebesar 1,49\% per tahun serta rerata tingkat kepadatan penduduk Indonesia sebesar 124 orang per $\mathrm{km}^{2}$. Kondisi demikian merupakan pangsa pasar potensial bagi peredaran gelap narkoba. ${ }^{1}$ Survei Badan Narkotika Nasional (selanjutnya disingkat BNN) hasil kerja sama dengan Pusat Penelitian Kesehatan Universitas Indonesia, tahun 2005 dan 2010, memperlihatkan angka prevalensi penyalahgunaan narkoba yang pernah pakai di tingkat rumah tangga relatif stagnan sekitar $2,4 \%{ }^{1,2}$ Artinya, ada satu diantara 42 orang yang berumur 10 - 59 tahun yang pernah pakai narkoba minimal satu kali seumur hidupnya. Mereka yang pakai narkoba setahun terakhir menunjukkan penurunan dari $0,8 \%$ (2005) menjadi $0,6 \%$ di tahun 2010 di tingkat rumah tangga.

Angka prevalensi penyalahguna yang pernah pakai suntik sekitar $0,27 \%$ di tahun 2005 dan cenderung turun menjadi $0,15 \%$ di tahun 2010. Mereka pakai narkoba suntik dalam setahun terakhir sekitar $0,22 \%$ atau 2 dari 1000 orang pakai narkoba suntik dalam setahun yang lalu di 2005. Angka tersebut semakin mengecil di tahun $2010(0,01 \%))^{2}$ Untuk menanggulangi semua keadaan tersebut pemerintah melalui Peraturan Menteri Kesehatan, menerapkan Terapi Rumatan Metadon pada pecandu narkoba untuk mengurangi dampak buruk yang dapat 
ditimbulkan atau dikenal dengan istilah Harm Reduction. Terapi Rumatan Metadon merupakan salah satu terapi pengganti yang diperlukan bagi pecandu narkoba untuk mengendalikan perilaku ketergantungannya dan juga sebagai salah satu upaya pengurangan dampak buruk yang dapat ditimbulkan. ${ }^{3}$

Metadon adalah opiat (narkotik) sintetis yang kuat seperti heroin (putaw) atau morfin, tetapi tidak menimbulkan efek sedatif yang kuat. Metadon biasanya disediakan pada program pengalihan narkoba, yaitu program yang mengganti heroin yang dipakai oleh pecandu dengan obat lain yang lebih aman.

Metadon bukan penyembuh untuk ketergantungan opiat: selama memakai metadon, penggunanya tetap tergantung pada opiat secara fisik. Tetapi metadon menawarkan kesempatan pada penggunanya untuk mengubah hidupnya menjadi lebih stabil dan mengurangi risiko penggunaan narkoba suntikan, dan juga mengurangi kejahatan yang terkait dengan kecanduan. Dan karena diminum, penggunaan metadon mengurangi penggunaan jarum suntik bergantian. Program metadon mempunyai dua tujuan pilihan. Tujuan pertama adalah untuk membantu pengguna berhenti memakai heroin (detoksifikasi), diganti dengan takaran metadon yang dikurangi tahap-demi-tahap selama jangka waktu tertentu. Tujuan kedua adalah untuk menyediakan terapi rumatan (pemeliharaan), yang memberikan metadon secara terus-menerus dengan dosis yang disesuaikan agar pengguna tidak mengalami gejala putus zat atau sakaw. ${ }^{4}$

Terapi metadon merupakan terapi substitusi pengganti adiksi opioda pengguna narkoba suntik berbentuk cair yang pemakaianya dilakukan dengan cara diminum. ${ }^{1}$ Metadon dipilih sebagai terapi utama substitusi karena memiliki efek menyerupai morfin dan kokain dengan masa kerja yang lebih panjang sehingga dapat diberikan satu kali sehari dan penggunaannya dengan cara diminum. Efek yang ditimbulkan metadon mirip dengan yang ditimbulkan heroin, namun efek "fly"-nya tidak senikmat biasanya pada metadon, sifat ketergantungannya tidak seburuk heroin dan gejala putus obatnya tidak seberat heroin.

Peserta terapi rumatan metadon sering merasa diri mereka cukup sehat untuk keluar dari program terapi. Hal ini dipengaruhi dengan pendidikan yang rendah. Peserta dengan pendidikan yang rendah sering tidak mengerti dan salah paham tentang terapi rumatan metadon dan merasa bahwa dirinya telah berhasil didetoksifikasi sehingga peserta keluar dari program sebelum waktunya. Meskipun angka drop out yang tinggi sekitar $79 \%$ dari peserta terapi, sebagian besar memutuskan untuk kembali menjalani terapi dengan berbagai alasan. Perbaikan dosis yang sesuai, pemantauan reaksi adiktif dan edukasi diperlukan untuk mengurangi kesalahpahaman pada peserta program terapi rumatan metadon untuk mengurangi angka drop out. $^{5}$

\section{Metode Penelitian}

Penelitian ini bersifat survey deskriptif dengan data retrospektif menggunakan data sekunder berupa data Drop Out pada penggunaan Metadon di Puskesmas Senen, Puskesmas Gambir dan Puskesmas Kemayoran Jakarta Pusat pada tahun 2014-2016.

\section{Hasil}

Pada tabel 1 dapat dilihat jumlah pasien Drop Out Terapi Rumatan Metadon di Puskesmas Senen dalam 3 tahun. Tahun 2014 berjumlah 9 orang dari 216 pasien yang terdaftar (4,2\%), tahun 2015 berjumlah 16 pasien dari 239 pasien yang terdaftar $(6,7 \%)$, dan tahun 2016 berjumlah 6 pasien dari 249 pasien yang terdaftar $(2,4 \%)$. 
Tabel 1. Angka Drop Out Terapi Rumatan Metadon di Puskesmas Senen pada Tahun 2014 - 2016

\begin{tabular}{ccccc} 
& Tahun & $\begin{array}{c}\text { Jumlah } \\
\text { Pasien } \\
\text { Terdaftar }\end{array}$ & $\begin{array}{c}\text { Jumlah } \\
\text { Pasien } \\
\text { Drop Out }\end{array}$ & Persentasi (\%) \\
\hline Tingkat Tahun Angka Drop Out & 2014 & 216 & 9 & $4,2 \%$ \\
& 2015 & 239 & 16 & $6,7 \%$ \\
& 2016 & 249 & 6 & $2.4 \%$ \\
\hline
\end{tabular}

Pada tabel 2 dapat dilihat terdapat 2 pembagian kelompok berdasarkan jenis kelamin yaitu, laki - laki dan wanita. Dari 31 sampel, pasien laki - laki yang drop out sebanyak 29 orang $(93,5 \%)$ dan pasien perempuan sebanyak 2 orang $(6,5 \%)$.

Dari tabel 3 dapat dilihat bahwa jumlah pasien Drop Out Terapi Rumatan Metadon di Puskesmas Gambir dalam 3 tahun. Pada tahun 2014 berjumlah 24 orang dari 120 pasien yang terdaftar $(20 \%)$, tahun 2015 bejumlah 34 orang dari 98 pasien yang terdaftar $(34,7 \%)$, dan tahun
2016 berjumlah 13 orang dari 87 pasien yang terdaftar $(15 \%)$.

Tabel 2. Klasifikasi Pasien Drop Out Terapi Rumatan Metadon di Puskesmas Senen Berdasarkan Jenis Kelamin

\begin{tabular}{ccc}
\hline Jenis & $\begin{array}{c}\text { Frekuensi } \\
(\mathrm{n})\end{array}$ & Persentasi (\%) \\
Kelamin & 29 & $93,5 \%$ \\
Laki - laki & 2 & $6,5 \%$ \\
Wanita & 31 & $100 \%$ \\
Total &
\end{tabular}

Tabel 3. Angka Drop Out Terapi Rumatan Metadon di Puskesmas Gambir pada Tahun 2014-2016

\begin{tabular}{ccccc} 
& Tahun & $\begin{array}{c}\text { Jumlah Pasien } \\
\text { Terdaftar }\end{array}$ & $\begin{array}{c}\text { Jumlah Pasien } \\
\text { Drop Out }\end{array}$ & $\begin{array}{c}\text { Persentasi } \\
(\%)\end{array}$ \\
\hline Tingkat & 2014 & 120 & 24 & $20 \%$ \\
Tahun & 2015 & 98 & 34 & $34,7 \%$ \\
Angka & 2016 & 87 & 13 & $15 \%$ \\
Drop Out & & & & \\
\hline
\end{tabular}

Pada tabel 4 dapat dilihat bahwa jumlah pasien Drop Out Terapi Rumatan Metadon di Puskesmas Kemayoran dalam 3 tahun. Pada tahun 2014 berjumlah 5 orang dari 54 pasien yang terdaftar $(9,2 \%)$, tahun 2015 berjumlah 11 orang dari 55 pasien yang terdaftar $(20 \%)$, dan tahun 2016 berjumlah 9 orang dari 47 pasien yang terdaftar $(19,1 \%)$.

Tabel 4. Angka Drop Out Terapi Rumatan Metadon di Puskesmas Kemayoran pada Tahun 20142016

\begin{tabular}{ccccc}
\hline & Tahun & $\begin{array}{c}\text { Jumlah } \\
\text { Pasien } \\
\text { Terdaftar }\end{array}$ & $\begin{array}{c}\text { Jumlah } \\
\text { Pasien } \\
\text { Drop Out }\end{array}$ & $\begin{array}{c}\text { Persentasi } \\
(\%)\end{array}$ \\
\hline Tingkat & 2014 & 54 & 5 & $9,2 \%$ \\
Tahun & 2015 & 55 & 11 & $20 \%$ \\
Angka & 2016 & 47 & 9 & $19,1 \%$ \\
Drop Out & & & & \\
\hline
\end{tabular}

Pada tabel 5 dapat dilihat bahwa terdapat 2 pembagian kelompok berdasarkan jenis kelamin yaitu, laki - laki dan wanita. Pada
Puskesmas Kemayoran 25 pasien yang drop out berjenis kelamin laki - laki (100\%). Pada tabel 6 dapat dilihat terdapat 5 pembagian kelompok 
berdasarkan usia yaitu, $<15$ tahun, $15-19$ tahun, $20-24$ tahun, $25-49$ tahun, dan $\geq 50$ tahun. Dari 25 pasien drop out, kelompok usia $20-24$ tahun sebanyak 1 orang (4\%) dan 25 - 49 tahun sebanyak 24 orang $(96 \%)$.

Tabel 5. Klasifikasi Pasien Drop Out Terapi Rumatan Metadon di Puskesmas Kemayoran Berdasarkan Jenis Kelamin

\begin{tabular}{ccc}
\hline Jenis Kelamin & $\begin{array}{c}\text { Frekuensi } \\
(\mathrm{n})\end{array}$ & Persentasi (\%) \\
\hline Laki - laki & 25 & $100 \%$ \\
Wanita & 0 & 0 \\
Total & 25 & $100 \%$ \\
\hline
\end{tabular}

Tabel 6. Klasifikasi Pasien Drop Out Terapi Rumatan Metadon di Puskesmas Kemayoran Berdasarkan Usia

\begin{tabular}{ccc}
\hline Usia & Frekuensi (n) & Persentasi $(\%)$ \\
\hline$<15$ & 0 & 0 \\
$15-19$ & 0 & 0 \\
$20-24$ & 1 & $4 \%$ \\
$25-49$ & 24 & $96 \%$ \\
$\geq 50$ & 0 & 0 \\
Total & 25 & $100 \%$ \\
\hline
\end{tabular}

\section{Pembahasan}

Hasil penelitian ini menunjukkan jumlah pasien drop out pada terapi rumatan metadon di Puskesmas Senen, Puskesmas Gambir dan Puskesmas Kemayoran dalam 3 tahun. Di Puskesmas Senen angka drop out tertinggi terjadi pada tahun 2015 yaitu sebanyak 16 pasien dari 239 pasien yang terdaftar (6,7\%). Di Puskesmas Gambir angka drop out tertinggi terjadi pada tahun 2015 yaitu 34 pasien dari 98 pasien yang terdaftar (34,7\%). Dan di Puskesmas Kemayoran angka drop out tertinggi terjadi pada tahun 2015 yaitu 11 pasien dari 55 pasien yang terdaftar 20\%. Dapat dilihat pada ketiga puskesmas angka drop out tertinggi terjadi pada tahun yang sama yaitu 2015.

Dari hasil penelitian di atas, pasien drop out pada terapi rumatan metadon baik di Puskesmas Senen maupun Puskesmas Kemayoran sebagian besar adalah berjenis kelamin laki - laki. Hal ini belum berubah dari data BNN pada tahun 2008 - 2012, tercatat sebagian besar penyalah guna narkoba adalah laki - laki dengan proporsi selalu di atas $80 \%$.

Dari hasil penelitian di Puskesmas Kemayoran kelompok umur yang paling banyak drop out terjadi pada kelompok umur $25-49$ tahun yaitu, 24 pasien dari 25 pasien drop out (96\%). Hal ini masih sama dari tahun $2009-$ 2013. Menurut data dari RSKO antara tahun 2009 - 2013 tercatat jumlah tersebar pasien narkoba ada pada kelompok 30 - 34 tahun. Besarnya proporsi penyalah guna narkoba pada kelompok umur dewasa perlu mendapat perhatian lebih, khususnya dalam hal pencegahan penyalahgunaan narkoba, yang harus tidak saja dilakukan oleh pemerintah melainkan juga oleh masyarakat khususnya keluarga. Orang dewasa bisa dengan mudahnya memperoleh obat baik di tempat umum seperti warung maupun di tempattempat tertentu seperti diskotik.

\section{Simpulan}

Berdasarkan penelitian yang telah dilakukan dengan mengambil data Drop Out pada Penggunaan Terapi Rumatan Metadon di Puskesmas Senen, Puskesmas Gambir dan Puskesmas Kemayoran Jakarta Pusat Pada Tahun 2014 - 2016, dapat ditarik kesimpulannya sebagai berikut:

1. Angka drop out tertinggi pada ketiga puskemas terjadi pada tahun 2015

2. Pasien drop out sebagian besar berjenis kelamin laki - laki

3. Kelompok umur terbanyak pada kelompok umur 25 - 49 tahun

4. Ditinjau Islam

\section{Saran}

Saran yang dikemukakan oleh penulis sebagai berikut:

1. Perlunya perhatian lebih dari pihak puskesmas terhadap peserta terapi rumatan metadon.

2. Dibutuhkan dukungan dari keluarga dan kesadaran dari peserta itu sendiri untuk menurunkan angka kejadian drop out.

3. Bagi peneliti selanjutnya diharapkan dapat melakukan penelitian dengan cakupan variabel 
yang lebih luas.

\section{Daftar Pustaka}

1. Badan Narkotika Nasional. Petunjuk Teknis Advokasi Bidang Pencegahan Penyalahgunaan Narkoba. 2008.

2. Badan Narkotika Nasional dan Pusat Penelitian Kesehatan UI. Survei Nasional Penyalahgunaan dan Peredaran Gelap Narkoba di Indonesia. 2010.

3. Menteri Kesehatan RI. Peraturan Menteri Kesehatan Program Terapi Rumatan Metadon (PTRM). Jakarta: Peraturan Menteri Kesehatan. 2013.

4. Komisi Penanggulangan AIDS. Pedoman Prosedur Pelaksanaan Program Pengurangan Dampak Buruk Bagi Pengguna NAPZA Suntik di Puskesmas. Jakarta. 2008.

5. Zhang, et al. Investigation of Repeat Client Drop-Out and Re-Enrolment Cycles in Fourteen Methadone Maintenance Treatment Clinics in Guangdong, China. 2015. 